\title{
Online cloud performance testing in social networks at peak demand scenarios
}

\author{
Anitha K L ${ }^{1}$, T.R. Gopalakrishnan Nair ${ }^{2}$ \\ ${ }^{1}$ Bharathiar University, India \\ ${ }^{1,2}$ Networks and Security Research Group, Advanced Reseach Centre, RRCE, Rajarajeswari Group of Institutions, India
}

\begin{tabular}{|c|c|}
\hline Article Info & ABSTRACT \\
\hline Article history: & Cloud computing assures to deliver reliable services through advanced data \\
\hline Received Mar 9, 2019 & $\begin{array}{l}\text { centers built on virtualized compute and storage technologies. Users } \\
\text { demanding more cloud services will be able to access applications and data }\end{array}$ \\
\hline Revised Jun 26, 2019 & from a Cloud anywhere in the world in a pay-as-you-go model. In this paper, \\
\hline Accepted Jul 9, 2019 & $\begin{array}{l}\text { we focus on cloud-based performance testing for the applications. We use } \\
\text { Load Storm testing tool to configure and test plans to measure the }\end{array}$ \\
\hline Keywords: & $\begin{array}{l}\text { performance of web applications in online social networks. The experimental } \\
\text { observations designed to assess the performance fluctuations of social }\end{array}$ \\
\hline $\begin{array}{l}\text { LoadStorm. } \\
\text { Network } \\
\text { Security }\end{array}$ & $\begin{array}{l}\text { networks on maximum consumer demand days have given specific data } \\
\text { pointers which could be utilized for further studies of web service } \\
\text { enhancements. }\end{array}$ \\
\hline
\end{tabular}

Copyright $@ 2020$ Institute of Advanced Engineering and Science. All rights reserved.

\section{Corresponding Author:}

Anitha K L,

Bharathiar University,

Coimbatore,India.

Email: anithak107@gmail.com

\section{INTRODUCTION}

Cloud computing continues to bringin new business models and computing paradigms, which enable on demand provisioning of computational and storage resources for multiple users at host level, network level and at application level. The consumers of the cloud are the end users and they can use infrastructure, software and platform as a service provided by the cloud by agreeing to the Service Level Agreement (SLA) specified by the cloud provider. The end users must verify the Quality-of-Service (QoS) provided in SLA before using the services in the cloud to achieve successful performance and dependability management of services. They can avail the services in a secure manner with low cost and demand driven basis. The major requirements of the end users for using the cloud services are lesser cost, privacy, availability, ease-of-use and assured security. The various cloud providers offers three types of clouds namely public, private and hybrid clouds [1]. The organizations/Enterprises or the individuals use public cloud based upon their computing requirements. The enterprise or an organization owns a private cloud for their internal use. They use private cloud to provide enough resources on demand basis to the employees in the organization. They can offer high level of security. A hybrid cloud is a combination of public and private cloud. The requirements/issues pertaining to the cloud providers are managing resources, utilization of resources, energy efficiency, cost efficiency and the capability to meet the end user needs. The Cloud Developer is an entity that lies between the end user and the cloud provider. The cloud developer must adhere to all technical details of the cloud, which are essential to meet the requirements of the end users and the cloud provider. From the QoS perspective, Cloud consists of a large pool of easily usable and accessible resources such as development platforms, hardware and services. This pool of resources can be dynamically reconfigured to optimum resource utilization. Moreover, these virtualized resources are typically exploited by a pay-per-use model in which guarantees are offered by the Infrastructure provider by means of customized 
SLA's [2]. Armbrust, M. et al has systematically framed cloud computing stating that the cloud computing consists of application software delivered in the form of services over the internet, and the hardware and systems software in the data centers that facilitate these services [3]. The real-time scalable resources such as applications, hardware, and third party services which can be accessible to users via, internet. In addition, the users pay only for the resources and services which they use by means of customized Service Level Agreement (SLA) having no knowledge of how a service provider uses an underlying technology infrastructure to support them. Depending upon the end-users service requests, the service load in Cloud Computing is dynamically changed [4]. Therefore appropriate allocation of load in the distributed environment is an effective solution for achieving the maximum usage of resources. Authors [5] propose a net priority scheduling for the optimal shecduling of the tasks for virtual machine load balancing.Virtualization converts the data center into an elastic cloud infrastructure wherein it can run the applications on demand therby provides performance and reliability. As the consumers are more dependent on availing the services in the cloud, scheduling of the tasks should be carried out in an efficient manner wherein all the virtual machines should be fully occupied.

\subsection{Problem Statement}

Web services have progressed far and wide into the society touching the life of every ordinary person. Most of the services offer interruption free service with varying response time based on peak demands arising out of important events happening across the world. To have a visibility of the performance degradation or service incapacitation, now people investigate models of assessment in tackling scenario based performance factors.

We tackled this problem through an analytical observation of three leading units of web services on critically dense and high demand events. In this paper, we discuss about the performance of web applications in online social networks and the rest of the paper is organized as follows. Section 2 describes testing web applications and Section 3 discusses about cloud based security testing and Section 4 discusses the performance testing. Section 5 shows the simulation results based on the social networks and Section 6 concludes the paper.

\section{TESTING WEB APPLICATION}

Web application is a program that keeps running in a browser environments and engaging different clients who can access the resources smoothly. A web application relieves the developer from the obligation of building a client for a particular sort of computer or a particular operating system as the customer keeps running in an internet browser. In this manner web application can keep running on any machine, running any operating with a browser supporting the specific application [6]. Testing is the process of executing a program with the objective of finding errors. The functionality and performance are the two basic elements for building a successful product. Functionality refers to what the application lets its users accomplish, including the transactions it enables and the information it renders accessible. Performance refers to the system 's capability to complete the transactions and to furnish the information quickly and accurately in spite of high multi-user interaction or constrained hardware resources [7]. Performance testing tools are utilized to decide the time required to carry out a task with the system. The performance tests can be checked for speed, consistency and the capacity to handle the load for a particular website. There are distinctive kinds of performance tests like load test, stress test, and volume test. The tool's compatibility with the software under test, its installation and setup, flexibility in testing are some of the issues that have been identified related to tools [8]. These approaches can enable a successful quantitative and qualitative analysis of the performance.

This performance testing is to verify whether system can meet its non-functional requirements which are identified in Software Requirement Specification (SRS) document or not. In current scenario there are a lot of websites on the internet it becomes essential to test the web applications for performance before launching [9]. The test tools allow the testers to create, manage and execute the test for a particular environment, which is maintained for precise test for a particular application [10]. Testing tools are used to perform testing in an easy manner and helps to simulate the test environment for a system which is under testing. They can automate the testing process and can make it much easier. Manual testing is very costlier wherein it requires too much effort and also it is time consuming. With the help of tools automated testing can be performed by reducing the cost, time and effort. The functional testing tools, black-box testing tools and white- box testing tools, bug tracking tools, performance testing tools are the various types of testing tools. Performance testing tools are used for different types of performance testing like load test, stress test, volume test and strength test. Testing tool enables the testers to create, manage and execute test in a particular environment, maintained for specific test for a particular application [11]. The performance-testing tool is to generate load for a web application. Load is represented by number of users accessing the tested 
application simultaneously. Because the testing tool only simulates these users, they are called virtual users. Each virtual user represents one individual user functioning with the application [12]. As the enterprise grows, it becomes more competitive and advanced for businesses to create high-quality software. While creating such software units it becomes mandatory to maintain the reliability and keepup the deadlines involved in the project should also met. Manual testing consumes larger amount of time and the efficiency involved in such processes are usually found to be low. Testing tools form a part of the automated testing and it supports software engineers to perform various testing tasks by using various testing tools [13]. The performance testing engrosses monitoring and recording the performance levels during regular, low and high stress loads. Internet users usually interact with the websites, in which many of them are dynamic in nature. These sites generate content to suit user requests instead of only serving static web pages. Due to this functionality and interactivity provided by these dynamic websites they are more appropriately well thoughtout as Web Applications [14].

\section{CLOUD BASED SECURITY TESTING}

Due to the growth of internet and the cloud computing technology, the web applications are also increasing. The developers create the web application and upload it on to the cloud wherein they need to concern about the load and the performance of the web application. There are various load testing tools available to measure the performance of web applications. Load storm is a cloud based load testing tool in which we can load test plans and scenarios to measure the performance of web applications. By using this tool we can generate graphs based on the criteria like throughput, response time, requests per second and the concurrent users [15-16]. The authors [16] discussed about the performance testing of the web applications like stress testing, load testing, capacity testing and the tools, which are used such as NeoLoad, Apache JMeter, Load Runner etc.

The security issues are increasing day by day as the business is growing quickly. Therefore, we need to think about cloud security testing which assures the business data that can be uploaded safely. And for the confidental data we need to do use encryption schemes for the safety of the data before uploading to the cloud. Authors [17] proposed a client side encryption strategy called Data Storage Lock Algorithm (DSLA) to safeguard the data from vulnerabilities. For identifying access methods to a system by using various tools and techniques used by the hackers can guarantee security of cloud solutions. Authors [18] presented the objectives of performance testing, the types and the tools for testing the performance of web applications. In view of the fact that, progressively more applications we can deploy on to the cloud, to measure the performance and to secure the application we need to use load testing tools and cloud security testing. Onpremises tools are needed for traditional application testing wherein cloud based testing gives much faster and scalable testing. In cloud based security testing, the applications are tested by using a tool which is hosted on to the cloud. The user has to upload the application or has to provide the Uniform Resource Locator (URL) into the online portal. The user can configure and initiate the test thereby provides the test results.

The strategies need to be well thought-out as adopting a cloud based application security testing is as follows [19]:

a. Scale: The solution requires scaling quickly by the growing business needs without causing the performance and the configuration issues.

b. Speed: The scanner must be fast by short turnaround times and have the capacity to run parallel scans.

c. Availability: The online solution should be highly available for the users and it calls for strong application management through a centralized console with characteristics for effortless collaboration.

d. Quality: The scanner should perform accurate scans and be able to make triaging of false positives and false negatives, simple and fast. It empowers the developers to resolve the known issues.

e. Cost: Agile methodologies not only require rapid scanning, but also require multiple iterations of security testing. These iterations should not gain unjustified incremental costs.

\section{CLOUD BASED PERFORMANCE TESTING}

We can perform Cloud Testing by using the cloud infrastructure so we do not need to install any resources. It reduces cost and time by simulating users across the world. We can test the performance of web application at both usual and peak traffic situations from millions of users accessing the application all over the world. The geographically dispersed load provides the most accurate representation of real-world traffic.

The cost effectiveness is one of the predominant factor that governs the cloud computing. Cloud helps you to create separate test regions for the applications as and whilst you want. Cloud based testing offers a cost effective way of testing the web applications. 
The advantages of the cloud based performance testing are as follows:

a. Testing Scalability

Cloud based performance testing is not restricted by a number of users, testing can be performed more sensible by hits from expected number of users.

b. Geographical Testing

Cloud based performance can be tested from any region where the application can be accessible.

c. Reduces Overall Cost

Installation and maintenance setup for hardware's reduces overall cost, if we go for cloud testing as a platform.

With all these advantages, there may be challenges correlated with cloud performance testing. Due to the fluctuating performance caused by the provider's network condition, the test result may not be always accurate. Sometimes there might be a probability of a service outage from the provider; thereby we may not always get same resources [20].

Miao et. al. proposed finite state machines as a model for testing web applications [21]. In [22] authors proposed state charts for testing the web applications. The Load Testing Automation Framework is used to perform realistic load testing of web applications. They propose a simple load and a realistic usage model for implementing load testing [23]. Authors provided a detailed survey on model based testing based on web applications [24]. Performance of the web applications can be monitored by testing and analyzing the web application. Performance testing tools like YSlow and the Firebug is used for analysing the performance of the web application with a minimal cost [25].

In this paper, we introduced network based assessment of web services mainly using the cloud systems for social network needs of the society. The assessment focused on the performance of the cloud web services on high demand days like Christmas Eve, Christmas and New Year day and characterized the various aspects of consumer requirement response capabilities. It shows a clear cleavage of performance variation in different web service capability which can lead to much better redesign of such services in future.

\section{SIMULATION}

We have considered online social network like facebook, twitter and linkedIn as an experimental setup. We have used LoadStorm as a testing tool to evaluate the performance of web application. We have scheduled the test for 20 minutes duration with 5 start users and 10 peak users with a linear pattern. We considered all available regions for the traffic sources. We have observed the performance of the web applications for the most popular social networks on Christmas eve day, Christmas day and on new year day of 2018-19. The test statistics related to the test involving facebook, twitter and linkedin are shown in Tables 1-3.

Table 1. Test Statistics of Facebook

\begin{tabular}{cccc}
\hline \multicolumn{4}{c}{ Test Statistics (Facebook) } \\
\hline Parameters & Christmas Eve & Christmas & New Year \\
Total Requests & 590 & 592 & 590 \\
Peak RPS & 0.70 & 0.70 & 0.70 \\
Average RPS & 0.49 & 0.49 & 0.49 \\
Peak Response Time & $140(\mathrm{~ms})$ & $308(\mathrm{~ms})$ & $133(\mathrm{~ms})$ \\
Average Response Time & $45(\mathrm{~ms})$ & $43(\mathrm{~ms})$ & $43(\mathrm{~ms})$ \\
Data Transferred & $1,844(\mathrm{MB})$ & $1,812(\mathrm{~KB})$ & $1,707(\mathrm{~KB})$ \\
Peak Throughput & $2.19(\mathrm{kB} / \mathrm{s})$ & $2.19(\mathrm{kB} / \mathrm{s})$ & $2(\mathrm{kB} / \mathrm{s})$ \\
Average Throughput & $1.54(\mathrm{kB} / \mathrm{s})$ & $1.51(\mathrm{kB} / \mathrm{s})$ & $1.42(\mathrm{kB} / \mathrm{s})$ \\
Total Errors & 0 & 0 & 0 \\
\hline
\end{tabular}

Table 2. Test Statistics of Twitter

\begin{tabular}{cccc}
\hline \multicolumn{4}{c}{ Test Statistics (Twitter) } \\
\hline Parameters & Christmas Eve & Christmas & New Year \\
Total Requests & 586 & 586 & 586 \\
Peak RPS & 0.70 & 0.70 & 0.67 \\
Average RPS & 0.49 & 0.49 & 0.49 \\
Peak Response Time & $343(\mathrm{~ms})$ & $344(\mathrm{~ms})$ & $227(\mathrm{~ms})$ \\
Average Response Time & $156(\mathrm{~ms})$ & $145(\mathrm{~ms})$ & $140(\mathrm{~ms})$ \\
Data Transferred & $2,906(\mathrm{MB})$ & $2,906(\mathrm{~KB})$ & $2,906(\mathrm{~KB})$ \\
Peak Throughput & $3.47(\mathrm{kB} / \mathrm{s})$ & $3.47(\mathrm{kB} / \mathrm{s})$ & $3.31(\mathrm{kB} / \mathrm{s})$ \\
Average Throughput & $2.42(\mathrm{kB} / \mathrm{s})$ & $2.42(\mathrm{kB} / \mathrm{s})$ & $2.42(\mathrm{kB} / \mathrm{s})$ \\
Total Errors & 0 & 0 & 0 \\
\hline
\end{tabular}


Table 3. Test Statistics of Linkedin

\begin{tabular}{cccc}
\hline \multicolumn{4}{c}{ Test Statistics (Linkedin) } \\
\hline Parameters & Christmas Eve & Christmas & New Year \\
Total Requests & 2148 & 1417 & 1838 \\
Peak RPS & 2.45 & 1.78 & 2.33 \\
Average RPS & 1.79 & 1.18 & 1.53 \\
Peak Response Time & $843(\mathrm{~ms})$ & $1,680(\mathrm{~ms})$ & $3,206(\mathrm{~ms})$ \\
Average Response Time & $175(\mathrm{~ms})$ & $283(\mathrm{~ms})$ & $245(\mathrm{~ms})$ \\
Data Transferred & $20.31(\mathrm{MB})$ & $17.86(\mathrm{MB})$ & $19.05(\mathrm{MB})$ \\
Peak Throughput & $22.81(\mathrm{kB} / \mathrm{s})$ & $22.1(\mathrm{kB} / \mathrm{s})$ & $24.54(\mathrm{kB} / \mathrm{s})$ \\
Average Throughput & $16.92(\mathrm{kB} / \mathrm{s})$ & $14.88(\mathrm{kB} / \mathrm{s})$ & $15.87(\mathrm{kB} / \mathrm{s})$ \\
Total Errors & 0 & 0 & 0 \\
\hline
\end{tabular}

The overall performance is the prime factor in evaluating the web application because it closely reflects the end consumer experience. Performance checking in cloud is not the same as that of conventional packages. Figures 1-3 shows the peak response time of facebook, twitter and linkedin. And Figure 4 shows the average response time comparison of facebook, twitter and linkedin. The test was carried out for the social networks like facebook, twitter and linkedin for Christmas eve, Christmas and on the New year day simultaneously.

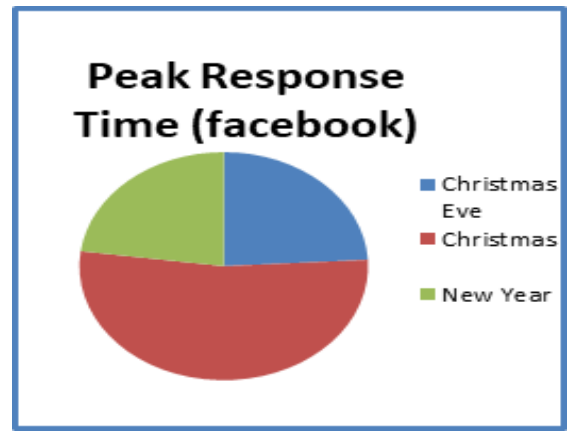

Figure 1. Peak response time of facebook

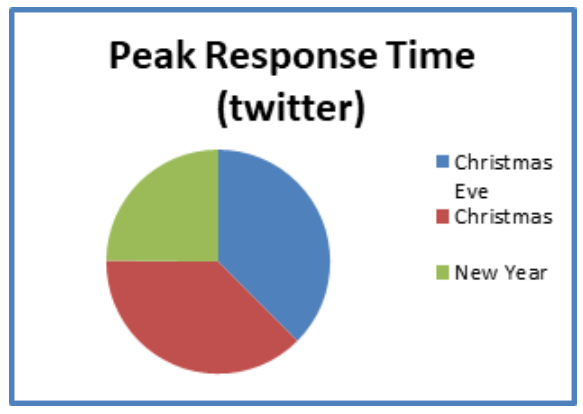

Figure 2. Peak response time of twitter

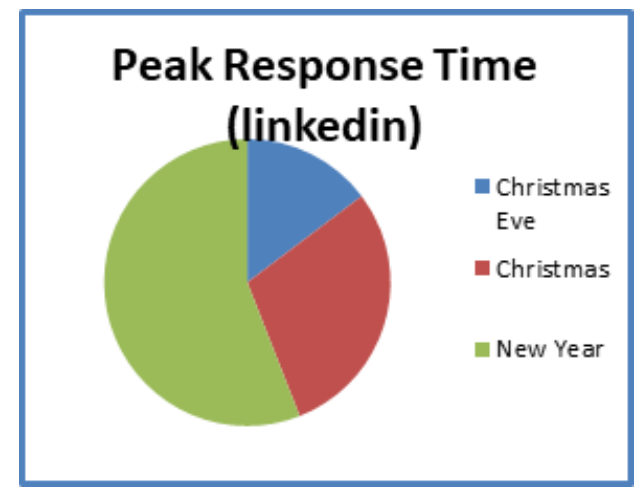

Figure 3. Peak response time of linkedin

The primary aim of the overall performance testing is to measure the diverse parameters such as system throughput, latency with converting quantity of parallel users having access to your software, with specific load profiles and numerous different performance metrics. In cloud environment, this becomes more typical with numerous virtual machines getting into play. Moving performance and load based software testing to the cloud, brings in the advantages of application testing through reducing capital and operational charges. Cloud-based performance testing allows us to get the most by means of utilising a value-effective method of testing packages at scale. It also permits the user to simulate load tests constituting tens of millions of concurrent users coming from multiple geographical places. 
The customer satisfaction is based on, the system access response by the user. In this aspect it is observed that, Facebook has organized servers communication systems and software architecture such that peak load service capability is currently met fully.

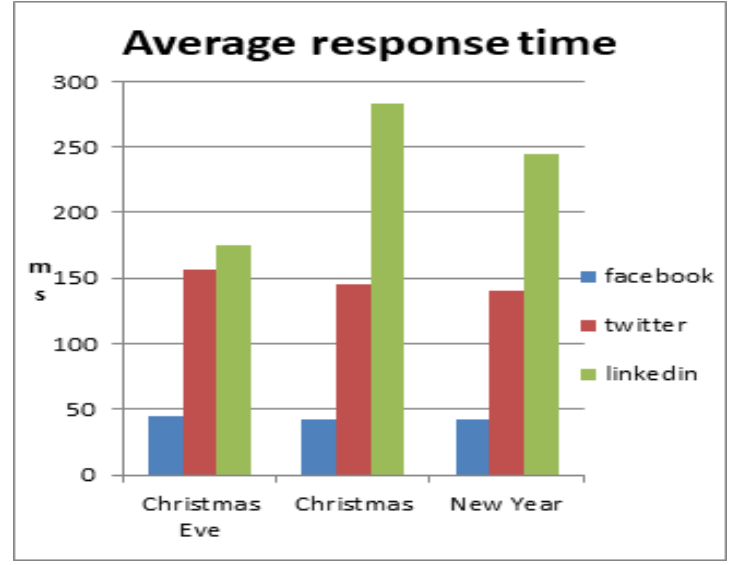

Figure 4. Average response time comparison of facebook, twitter and linkedin

\section{CONCLUSION}

Enterprises can test the performance of web applications by cloud-based testing services. It can save substantial cost and developmental effort in realizing the in-house testing tool. We discussed about the advantages of cloud security testing and cloud performance testing. We evaluated the performance of online social networks like facebook, twitter and linkedin in certain peak performance period using cloud based testing tool. This study reveals a comparative evaluation of technology based on user experience with respect to a group of most popular social sites. It adds value to the effort of caliberating social network performance evaluation and design enhancements.

\section{REFERENCES}

[1] Zhang, Q., Cheng, L. \& Boutaba, R. (2010), "Cloud computing: State-of-the-art and research challenges", Journal of Internet Services and Applications, 1(1),7-18. DOI 10.1007/s13174-010-0007-6.

[2] A. Tikotekar, G. Vallee, T. Naughton, H. Ong, C. Engelmann, S. Scott, A. Filippi, "Effects of virtualization on a scientific application running a hyperspectral radiative transfer code on virtual machines", in Proceedings of 2nd Workshop on System-Level Virtualization for High Performance Computing (HPCVirt 08) (Glasgow, UK, 2008): pp. 16-23.

[3] Armbrust, M. et al. (2009), "Above the Clouds: A Berkeley View of Cloud Computing” (Technical report EECS2009-28). UC Berkeley, Retrieved From http:/ /www.eecs.berkeley .edu/Pubs /TechRpts /2009/ EECS-200928.html.

[4] K. Xiong, H. Perros, "Service performance and analysis in cloud computing", in Proceedings of Congress on Services - I (SERVICES 09). IEEE Computer Society Washington 2009, 693-700.

[5] Anitha K L, T.R. Gopalakrishnan Nair, "Priority Alteration Scheme for Load balancing in Virtual Machines of Cloud Computing", International Journal of Research in Electronics and Computer Engineering (IJRECE), ISSN: 2393-9028 (PRINT) | ISSN: 2348-2281 (Online), Vol. 7 Issue 1 (January- March 2019), pp. 379 384.

[6] Dr. S. M. Afroz, N. Elezabeth Rani and N. Indira Priyadarshini, "Web application: The study on comparing software testing tools", International Journal of Computer Science and Telecommunications, Volume 2, Issue 3, June 2011.

[7] H. Sarojadevi, "Performance Testing: Methodologies and Tools", Journal of Information Engineering and Applications, ISSN 2224- 5758 (print) ISSN 2224-896X (online) Vol 1, No.5, 2011.

[8] Rina and Sanjay Tyagi, "Comparative study of performance testing tools", International Journal of Advanced Research in Computer Science and Software Engineering. Volume 3, Issue 5, May 2013.

[9] Dr. Manju Kaushik, Pratibha Fageria, "Performance testing tools: A comparative study", International Journal of Innovative Science, Engineering \& Technology. Vol. 1 Issue 4, June 2014.

[10] Tanuj Wala, "A Comparative Study of Web Service Testing Tools", International Journal of Advanced Research in Computer Science and Software Engineering. Volume 4, Issue 2, February 2014.

[11] Shagun Bhardwaj, "Performance Testing Tools: A Comparative Analysis", International Journal of Engineering Technology, Management and Applied Sciences, Volume 3 Issue 4, April 2015. 
[12] Manjit Kaur and Raj Kumari, "Comparative Study of Automated Testing Tools: TestComplete and QuickTest Pro", International Journal of Computer Applications. Volume 24-No.1, June 2011.

[13] Shruti N. Pardeshi, "Study of Testing Strategies and availableTools", International Journal of Scientific and Research Publications. ISSN 2250-3153, Volume 3, Issue 3, March 2013.

[14] S. Elbaum, S. Karre, G, Rothermel, "Improving web application testing with user session data" in Proceedings of 25th International Conference on Software Engineering (ICSE`03), 3-10 May 2003, pp. 49- 59.

[15] Bhathiya Wickremasinghe, Roderigo N. Calherios, "Cloud Analyst: A Cloud-Sim-Based Visual Modeler For Analyzing Cloud Computing Environments And Applications", Proc of IEEE International Conference On Advance Information Networking nd Applications, 2010.

[16] Bhatti S and Kumari, "Comparative Study of Load Testing Tools", International Journal of Innovative Research in Computer andCommunication Engineering (An ISO 3297: 2007 Certified Organization) Vol. 3, Issue 3, March 2015.

[17] Anitha K L, T.R. Gopalakrishnan Nair, "Data storage lock algorithm with cryptographic techniques", International Journal of Electrical and Computer Engineering (IJECE), ISSN: 2088-8708, Vol. 9, No. 5, October 2019, pp. 3843 3849.

[18] Ms. S. Sharmila and E. Ramadevi, "Analysis of Performance Testing on Web Applications", International Journal of Advanced Research in Computer and Communication Engineering. Vol. 3, Issue 3, March 2014: 2319-5940, Pg. No. 5258-5260.

[19] V. Prakash and S. Gopalakrishanan, "Cloud Computing Solution - Benefits and Testing Challenges", Journal of Theoretical and Applied Information Technology. Vol. 39 No.2, 15 May 2012, pp. 114-118.

[20] https://www.softwaretestinghelp.com/cloud-performance-testing/[ Last Updated:August 31, 2018$].$

[21] Miao, H. K., Chen, S. B., \& Zeng, H. W. (2011). Model-based testing for Web applications. JisuanjiXuebao(Chinese Journal of Computers), 34(6), 1012-1028.

[22] Bansal, P., \& Sabharwal, S. (2013, August), "A model based approach to test case generation for testing the navigation behavior of dynamic web applications", Proceedings of the 2013 Sixth International Conference on Contemporary Computing (IC3) (pp. 213-218).

[23] Wang X., Zhou B. \& Li W. 2013, "Model-based load testing of web applications", Journal of the Chinese Institute of Engineers. 36(1): 74-86.

[24] Dias, N. A. C., Subramanyan, R., Vieira, M., \& Travassos, G. H. (2007, November), "A survey on model-based testing approaches: a systematic review”, Proceedings of the 1st ACM InternationalWorkshop on Empirical Assessment of Software Engineering Languages and Technologies: Held inConjunction with the 22nd IEEE/ACM International Conference on Automated Software Engineering (ASE) 2007 (pp. 31-36).

[25] Proko E. \& Ninka I. 2013. Analyzing and Testing Web Application Performance. International Journal of Engineering and Science. 3(10): 47-50.

\section{BIOGRAPHIES OF AUTHORS}

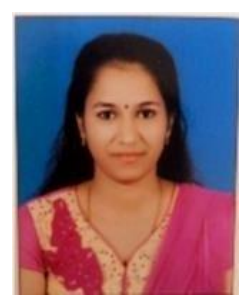

Anitha K. L. is a research scholar in the Department of Computer Science, Bharathiar University, Coimbatore, India. Anitha K L received post graduate degree in Master of Computer Applications and B.Sc. degree in Computer Science from the University of Kerala. Her research interests include cloud computing security, virtualization, data center and networking and distributed computing.

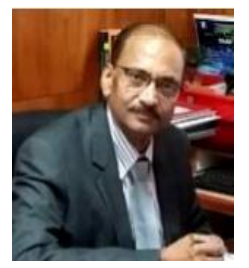

T.R. Gopalakrishnan Nair, a Fellow of Institution of Engineers, has 34 years of experience in professional field spread over Research, Industry and Education. Currently, he is the Rector for Rajarajeswary Group of Institutions in India. He was the Aramco Endowed Chair in Technology in PM University, KSA. He holds degrees M.Tech. (I.I.Sc., India) and a Ph.D. in Computer Science. His areas of interest include Advanced networks, Cognitive Systems and Multidisciplinary studies including Brain and physical systems. He is a senior member of IEEE, ACM and few other professional bodies. 